\title{
Analysis and Prevention of Legal Disputes in College Education Management
}

\section{Li Ma}

\author{
Yancheng Kindergarten Teachers College, Yancheng, Jiangsu, 224000, China
}

Keywords: colleges and universities; education management; legal disputes; prevention discussion

\begin{abstract}
With the expansion of the scale of higher education institutions and the rising number of enrolled students, the environment that college education management face has become more complicated, and a large number of legal disputes have emerged. Under the leadership of the basic strategy "rule by law", the Ministry of Education clearly stated that it is necessary to adhere to the basic policy of "ruling the school by law". Colleges and universities should increase the degree of emphasis on "ruling the school by law", improve and perfect the management system, standardize the management behavior, and make more efforts in strengthening the awareness of the rule of law and improving the management level of the rule of law.
\end{abstract}

\section{Introduction}

In recent years, as countries and societies pay more and more attention to education, university education has gradually received more and more attention, and the number of undergraduates has also shown an increasing trend year by year. This is very important for the future development of the country. However, with the increase in the number of college students, college education management is faced with more serious problems. The frequent legal disputes in university education management have greatly affected the quality of university management and affected the students' learning and living environment. Therefore, they must be effectively promoted. The management quality of colleges and universities, to create a good learning and living environment for students, colleges and universities should actively take effective measures to solve the legal disputes in the process of education management, to develop more comprehensive preventive measures.

\section{The Basic Classification of Legal Disputes in College Education Management}

There are many reasons for legal disputes in college education management. In practice, the types of legal disputes in college education management are also diversified. Therefore, to prevent legal disputes in education and management, one need to analyze the classification of legal disputes in university education management as a precondition, take the problem as the guide, and use the specific types of legal disputes as a basis to find the root of the problem. Appropriate preventive mechanisms are in place to truly achieve the rule of law.

\subsection{College students' mental health problems in legal disputes}

With the continuous development of the economic globalization, different cultures in various countries have continuously flooded into China. As college students receiving faster knowledge and culture, they are the first to be influenced by foreign cultures. Since the minds of undergraduates are not yet fully mature, they are conducting The process of cultural understanding lacks a certain ability to discriminate, which lays a hidden danger for the influence of bad culture. College students are vulnerable to adverse influences such as money worship and materialism, and have a greater impact on mental health [1]. In addition, with the popularization of Internet technology, a large amount of negative information is flooded with the Internet. Undergraduates are also affected by the unhealthy information in the process of browsing information, thus creating certain psychological problems, such as lack of self-confidence. In the process of interpersonal communication, tensions, mental depression, etc. occur. These psychological problems do not cause the attention of students and 
schools in the early stages, and their development leads to the development of more serious mental health problems, leading to the emergence of legal disputes in college education management.

\subsection{Legal disputes in students' accidental injury accidents}

In the management of institutions of higher learning, accidents involving student accidents are a high incidence of legal disputes. The "Measures for Dealing with Student Injury Accidents" issued by the Ministry of Education defines the accidental accidents of students. The "Student Injury Accident Treatment Measures" clarifies the time and space for students' accidental injury accidents: in terms of time, the school's teaching activities or school-organized off-campus activities are spatially defined as the places where the school has administrative responsibilities. For the specific cases of accidental injury accidents in college students, different legal solutions should be adopted.

The first is accidental injury to students caused by school teaching and living facilities. The implementation of school's teaching and living needs to meet certain safety standards. In the case where the implementation meets the safety standards, if the school has no fault in management, it should not bear civil liability ${ }^{[2]}$. In the actual situation, how to prove that the school is not mismanaged is quite complicated, it is difficult to prove that there is no mismanagement.

The second is accidental injury to students caused by food safety issues on campus. At the stage of higher education, most of the time spent by each student is spent at school. The school is not only an educational place but also a place of life for students. Therefore, university management is a very complicated systematic project. In the management of universities, schools must not only manage the teaching facilities but also manage the living facilities on campus. For example, canteen management also plays an important role in campus management. Canteen management is related to students' food safety. Often when a food safety accident occurs in a canteen at a university, it will not only cause student complaints, but also cause college students to carry out an online dissemination of the incident and cause public opinion.

Third, accidental injuries caused by the deterioration of student relations. Some of the accidental student accidents were caused by students' own negligence and poor school management. Others were intentional injuries caused mainly by unhealthy relationships between classmates. For the latter, colleges and universities also need to bear the responsibility to adapt to the fault. The school is obliged to carry out ideological education on students and prevent students from having bad behavior.

The fourth is student suicide. In recent years, the accidents of university students committing suicide have frequently been exposed, including some domestic first-class "985" and "211" universities. There are many causes of student suicide, some are due to academic performance problems, excessive pressure; some because of emotional problems; some because of the vicious relationship with classmates or teachers. In the suicide incident of college students, it is not only schools that need to take responsibility, but their families also need to take corresponding responsibilities.

In addition, there are accidental injury accidents among college students caused by accidental injuries to students, physical injury caused by students' sudden illnesses, and so on. This is not exhaustive. In such events, the only precondition for the school to be exempt is to prove that there is no fault in the management.

\subsection{Legal disputes arising from student's daily management}

In the higher education stage, the pressure on students to go to school is relatively small. Completion of schooling depends not only on school training, but also on student autonomy ${ }^{[3]}$. The main cause of legal disputes in the daily management of college students is the conflict between the administrative management of universities and the individual rights of students; the legal disputes in the distribution of competitive resources, such as award evaluation.

In order to achieve the purpose of administrative management in colleges and universities, there may be administrative behaviors that infringe the rights of students in the actual administrative management. For example, in the student dormitory management, some schools will carry out surprise inspections. Even if the students are not in the dormitory, the dormitory administrator can 
open the student's personal dormitory to check the illegal electrical condition and confiscate the electrical equipment that is not allowed in the dormitory, which violates the student's privacy and property rights. In addition, some colleges and universities have included the use of illegal electrical appliances in the criteria for the evaluation of scholarships. These practices can easily lead to legal disputes between students and schools.

In the distribution of competitive resources such as awards, appraisals, scholarships, insurance research qualifications, and inter-school exchange quotas, it is often easy to trigger legal disputes. On the one hand, some schools' awards and evaluation rules themselves have flaws, and cannot guarantee

the right of all students to participate fairly ${ }^{[4]}$. On the other hand, the procedures for award evaluation and appraisal and certain special bonus items are generally easy to cause as legal disputes. The practice of evenly distributing competitive resources in some schools not only does not contribute to fairness, but also leads to legal disputes. For example, in the course of scholarship evaluation, some schools will evenly distribute the total amount of scholarships that students receive, triggering a wider range of conflicts. Or use scholarships as funding for class activities. Not only does it fail to reach the goal of advanced scholarship rewards and motivation, it will make students lose their incentive to learn.

\subsection{Legal disputes arising from disciplinary actions against students}

Student disciplinary action is part of the day-to-day management of colleges, but due to the high incidence of legal disputes, it is listed separately. The stage of higher education is different from the stage of compulsory education. Schools have greater penalties for students who violate disciplines. Not only can they be used as references for awards, appraisals, and postgraduates, but they can also make decisions about disqualification when necessary. The legal disputes that arise in the practice of student disciplinary actions generally focus on whether the disposition of facts is conclusive, whether the school regulations and disciplines are contrary to laws and regulations, whether the punishment procedures are standardized, and whether the punishment is appropriate or not. In the aspect of disciplinary punishment for college students, it is necessary to further improve the student's rights relief mechanism, improve the university students' complaint mechanism, and make students and the school as equal subjects communicate with each other to reduce disputes.

\subsection{Legal disputes among workers and staff members caused by college education management}

In order to continuously improve the education and management of colleges and universities, we will provide more comfortable schooling environments. In general, college logistics management departments will employ a large number of workers. Workers and staff members have different work contents and the quality of personnel is uneven, and management has certain difficulties. In the case of work-related personnel's work mistakes, etc., colleges and universities work attendance management departments generally take punitive measures, such as fines. In this case, legal disputes between workers and school workers are easily caused. In addition, if colleges and universities hire workers with poor quality in employment, it may easily lead to conflicts between workers and staff, causing more complicated legal disputes.

\section{The Causes of Legal Disputes during College Education Management}

\subsection{The insufficient mental health education for college students}

For college students who are in the critical stage of growth, their outlook on life and world outlook are forming. At this time, teachers' education and guidance are needed, so as to form the correct orientation of life values and lay a good foundation for future growth and development. However, judging from the current form of university education, compared to the education at the middle and senior high school level, university education appears to be too diffuse and unsatisfactory for the level of education of the students. This is particularly evident in the aspects of psychological education and personality education. Caused by the lack of personality education in college students, 
coupled with the adverse effects of all types of negative information, college students are likely to form a certain degree of mental health problems ${ }^{[5]}$. Although the scientific and cultural quality of college students is high, if they do not have a sound personality and a correct view of life, they cannot adapt to the actual needs of social development and form an education result in unbalanced development of knowledge and mental health. This leads to the emergence of students. Certain psychological problems have raised the chance of college management disputes.

\subsection{The lack of a sound and complete prevention mechanism for educational disputes in colleges and universities}

All along, college education has focused on improving students' scientific and cultural quality. All teaching activities have also been carried out around this purpose, and there has been insufficient attention to legal disputes in education and management. In other words, due to the lack of sufficient attention to legal disputes in education and management, some potential schools of educational management and legal disputes are not easily noticeable. When serious legal consequences arise from educational management legal disputes, it is already too late to take effective measures. This is also one of the main reasons for the frequent occurrence of legal disputes in education management. For legal disputes in college education and management, we must start from multiple aspects to achieve prevention. If we want to achieve such an effect, we should actively carry out relevant legal education for college students, so that college students can establish a certain degree of management awareness, thereby reducing The occurrence of legal disputes in college education management, but due to the neglect of education and management legal disputes education in the process of university education, leading to educational management legal disputes occur from time to time.

\section{The effective prevention of legal disputes in colleges and universities}

Although college students already have basic learning abilities, teachers should still focus on the prevention of innovation in the way they work in the prevention of legal disputes in college education. Because for college students, they generally focus on learning professional knowledge. They do not attach importance to school ideological and political education. If teachers do not pay attention to certain methods during the work process, the students' educational effects can be imagined. For example, colleges and universities or teachers can organize students together to carry out centralized and systematic learning of General Secretary Xi's important speeches, and always use the achievement of work goals and the series of important speeches of General Secretary Xi to promote the ideological and political work of college students. In the practical process of ideological and political education of college students, the rational optimization of the work model is an important prerequisite for improving the quality of work. In the limited educational time, the maximization of work results, the optimization of results, and the actual improvement of the quality of ideological and political work.

At the same time, colleges and universities should make full use of the information advantages of the Internet to actively carry out educational activities, such as some network hot spots, teachers should make full use of these phenomena, to carry out education management legal dispute prevention education for college students, use these bad phenomena to wake up college students, and cultivate college students to comply with The law-abiding spirit, if you want to do this, should maintain sensitivity to political events, be good at capturing news hotspots, and properly process and organize them, and then become a good material for improving the quality of university ideological and political education. College students' legal awareness, developing correct outlook on life and values and good psychological quality, from the source to curb the occurrence and development of legal disputes in college education management, and improve the quality of legal dispute prevention in colleges and universities. 


\section{Conclusion}

To sum up, the legal disputes in colleges and universities' education and management are the work content that colleges and universities should pay close attention to. In this process, colleges and universities should continue to innovate and improve work strategies to improve the effectiveness of legal dispute prevention in colleges and universities, and suppress college education from the source. Managing legal disputes creates a good learning environment for students.

\section{References}

[1] Wang Yujing. Problems of Legal Disputes in the Management of College Students in the New Era and Ways to Solve Them, Chinese Glamour, 2018(2):26-27.

[2] Hu Qianhui. Questions on Legal Disputes in the Management of College Students, Journal of Tongling College, 2016(1):91-93.

[3] Zhang Dongmei \& Zheng Tianfeng. On the Difficulties and Perfecting Ways of Judicial Decision-making in University Education Management Disputes, Gansu Theory Journal, 2015 (4):121-126.

[4] Fan Xiao. Legal Disputes of College Students Management and their solutions, Journal of Gannan Teachers College, 2015(12):85-88.

[5] Sun Rongli \& Meng Lingjun. Research on the Problems and Countermeasures of Disobedience Procedures for Students in Colleges and Universities_— the Investigation and Analysis Based on Student Management Staff in Some Universities in Heilongjiang, Heilongjiang Research on Higher Education, 2015(6):64-67. 